\title{
SAMUS COUNTER LIFTING
}

FIXTURE

D-ZERO ENGINEERING NOTE \#3740.000-EN-494

Herman J. Stredde

May 27, 1998

Approved:

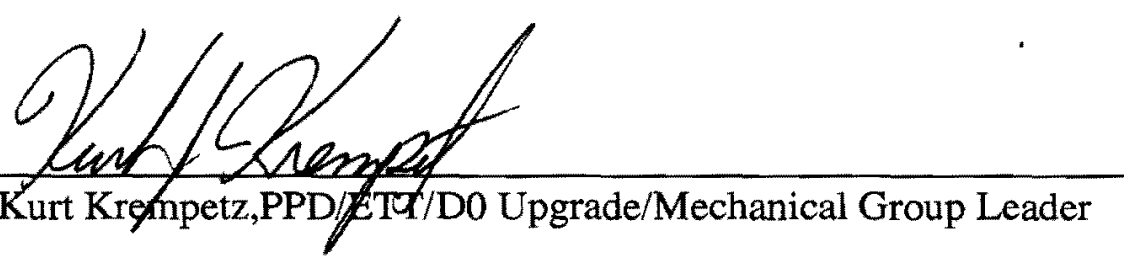




\section{BELOW-THE-HOOK LIFTING DEVICE Engineering Note Cover Page}

Lifting Device Numbers:

FNAL Site No.:

Div. Specific No.:

Asset No. if applicable

ASME B30.20 Group: if applicable if applicable (check one)

$\checkmark$ Group I Structural and Mechanical Lifting Devices Group II Vacuum Lifting Devices Group III Magnets, Close Proximity Operated Group IV Magnets, Remote Operated

Device Name or Description: SAMUS CHAM EER LIFTING FIXTURE

Device was: $\quad$ Purchased from a Commercial Lifting Device Manufacturer mfg. name:

(check all applicable) $\backslash$ Designed and Built at Fermilab

Designed by Fermilab and Built by a Vendor

Assy drawing number:

Provided by a User or Other Laboratory

Other. Describe:

Engineering Note Prepared by: H.STREDDE D Date : 5.27 .98

Engineering Note Reviewed by: H.CARter Date: 7-15-98

Lifting Device Data:

Capacity: 3000 LBS

Fixture Weight:

Service: normal heavy severe (refer to B30.20 for definitions)

Duty Cycle: __ $\quad 8,16$ or 24 hour rating (applicable to groups III, and IV) Inspections Frequency:

Rated Load Test by FNAL (if applicable): Date:6.9.98 Load: $4300 \mathrm{LBS}$

Check if Load Test was by Vendor and attach the certificate.

Satisfactory Load Test Witnessed by:

Signature (of Load Test Witness):

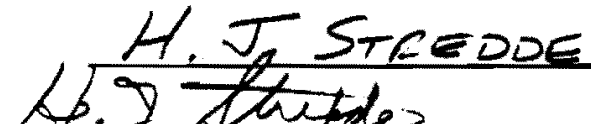

Notes or Special Information:

FIXTURE TO BE USEO FOR HANDLING/LIFTING OF

SAMUS MUON CHAMBERS. 
A lifting fixture has been designed to handle the Samus counters. These counters are being removed from the D-zero area and will be transported off site for further use at another facility. This fixture is designed specifically for this particular application and will be transferred along with the counters.

. The future use of these counters may entail installation at a facility without access to a crane and therefore a lift fixture suitable for both crane and/or fork lift usage has been created The counters weigh approximately $3000 \mathrm{lbs}$. and have threaded rods extended through the counter at the top comers for lifting. When these counters were first handled/installed these rods were used in conjunction with appropriate slings and handled by crane. The rods are secured with nuts tightened against the face of the counter. The rod thread is M16x2( .625" dia.) and extends 2"(on average) from the face of the counter. It is this cantilevered rod that the lift fixture engages with " $C$ " style plates at the four top corners. The strongback portion of the lift fixture is a steel rectangular tube 8"(vertical) x 4" x.25" wall, 130" long. 1.5 " square bars are welded perpendicular to the long axis of the rectangular tube at the appropriate lift points and the " $\mathrm{C}$ " plates are fastened to these bars with $3 / 4-10$ high strength bolts -grade 8. Two short channel sections are positioned-welded- to the bottom of the rectangular tube on 40 " centers, which are used as locators for fork lift tines. On the top are lifting eyes for sling/crane usage and are rated at $3500 \mathrm{lbs}$. safe working load each-VERTICAL LIFT ONLY!

The fixture has been designed in accordance with ANSV/ASME B30.20-1985, Standard for Below-The-Hook Lifting Devices. This standard requires a safety factor of three based on the yield strength of the material on all components.

\section{Component Data:}

$8 \times 4 \times .25$ wall steel tube, $\mathrm{f}_{\mathrm{y}}=46 \mathrm{KSI}, \mathrm{f}_{\mathrm{a}}=46 / 3-15.33 \mathrm{KSI}$ $I_{x x}=45.1$ in $^{4}, I_{y y}=15.3$ in $^{4}, S_{x x}=11.3$ in $^{3}$, Area -5.59 in $^{2}$

Hanger Bars, Low Carbon steel, $\mathrm{f}_{\mathrm{y}}-30 \mathrm{KSI}, \mathrm{f}_{\mathrm{a}}=30 / 3=10 \mathrm{KSI}$ $\mathrm{I}_{\mathrm{xx}}-\mathrm{I}_{\mathrm{yy}}-0.422 \mathrm{in}^{4}, \mathrm{~S}=0.5625 \mathrm{in}^{3}$, Area $=2.25 \mathrm{in}^{2}$

"C" plate, Low Carbon steel, $f_{y}=30 \mathrm{KSI}, \mathrm{f}_{\mathrm{a}}=30 / 3=10 \mathrm{KSI}$ $\mathrm{I}_{\mathrm{xx}}=0.837$ in $^{4}, \mathrm{~S}_{\mathrm{xx}}=0.705 \mathrm{in}^{3}$

Bolts, Grade 8 steel, $f_{y}-120 \mathrm{KSI}, f_{a}-120 / 3-40.0 \mathrm{KSI}$

Rectangular Tube (Fig. 1)

Max. Moment $=45$ x 1500 $=67,500 \mathrm{lb}$.-ins.

Bending stress, $\mathrm{f}_{\mathrm{b}}=\mathrm{M} / \mathrm{S}-67,500 / 11.3-5973 \mathrm{psi}<15.33 \mathrm{KSI}$

Shear stress, $f_{s}=1500 / 5.59-268$ psi $<15.33 \mathrm{KSI}$

Deflection @ ctr -(Pa/24EI $)\left(31^{2}-4 a^{2}\right)=0.092 "$

Hanger Bars (Fig. 1)

Max. Moment-Pl-4.125 X 750- 3100 psi

$\mathrm{f}_{\mathrm{b}}=3100 / 0.5625-5511 \mathrm{psi}<10 \mathrm{KSI}$

deflection @ end-PL/3EI $0.0015 "$

Bolts

Max. Moment-.375 x 750-281 lb-ins.

$F_{b}=(281 \times .375) / .015-7,025 \mathrm{psi}<40 \mathrm{KSI}$

Shear stress-750/.302-2500 psi

Bearing Stress $-750 /(.75 \times .75)-1333 \mathrm{psi}$

"C" plates(Fig. 2)

Max. stress $-\mathrm{P} / \mathrm{a}+\mathrm{Mc} / \mathrm{I}=750 /(2.5 \times .75)+(1.625 \times 750)(1.25) / 0.837=2220 \mathrm{psi}<10 \mathrm{KSI}$

Tear out through bolt hole to top of " $C$ " plate $-750 /(1.375 \times .75)=727 \mathrm{psi}$

This lifting fixture will be load tested to $1.25 \mathrm{x}$ rated load of $3000 \mathrm{lbs} .-3750 \mathrm{lbs}$. The test will include lifts at the fork lift location as well as the points where the crane picks are made. 

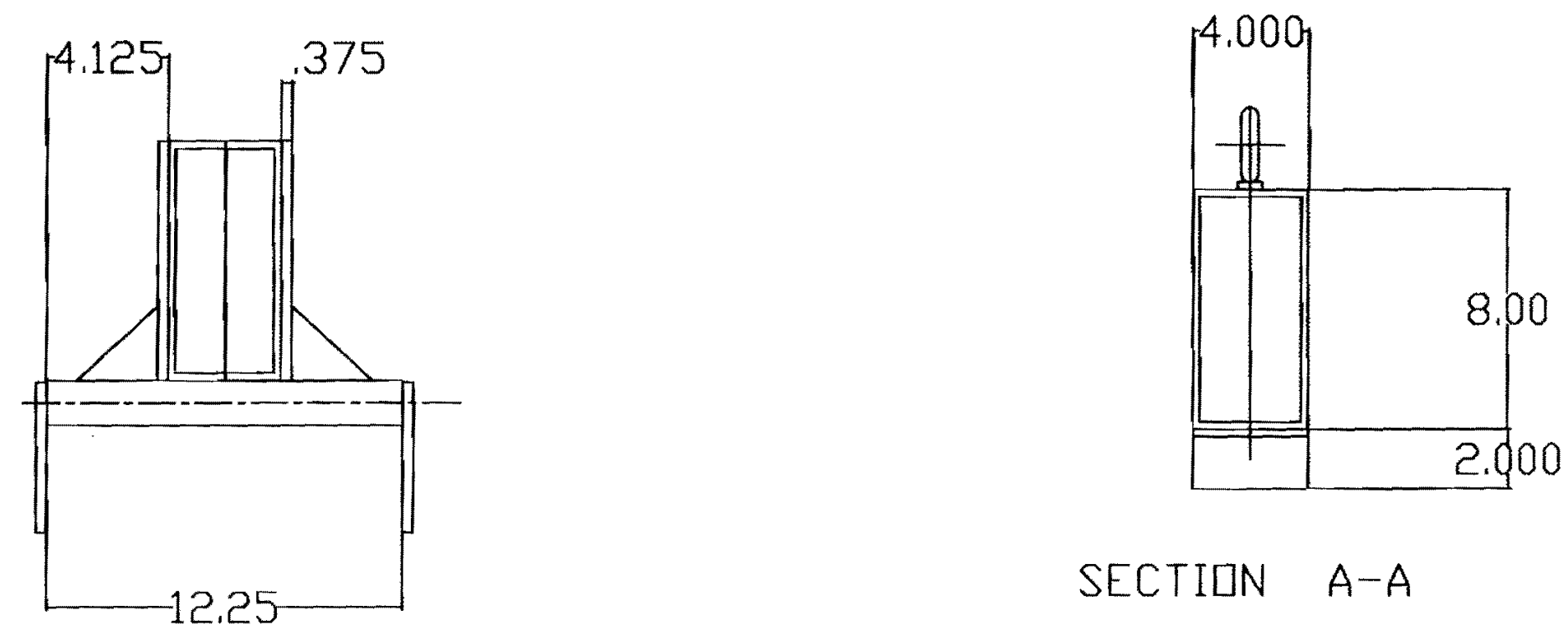

SECTION A-A

$-136.0000$

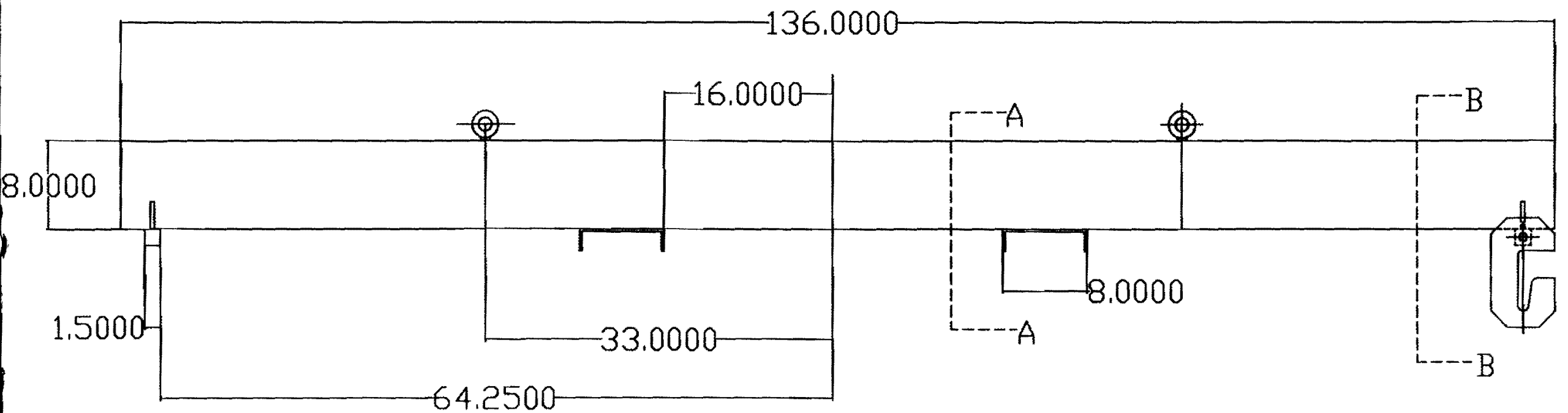




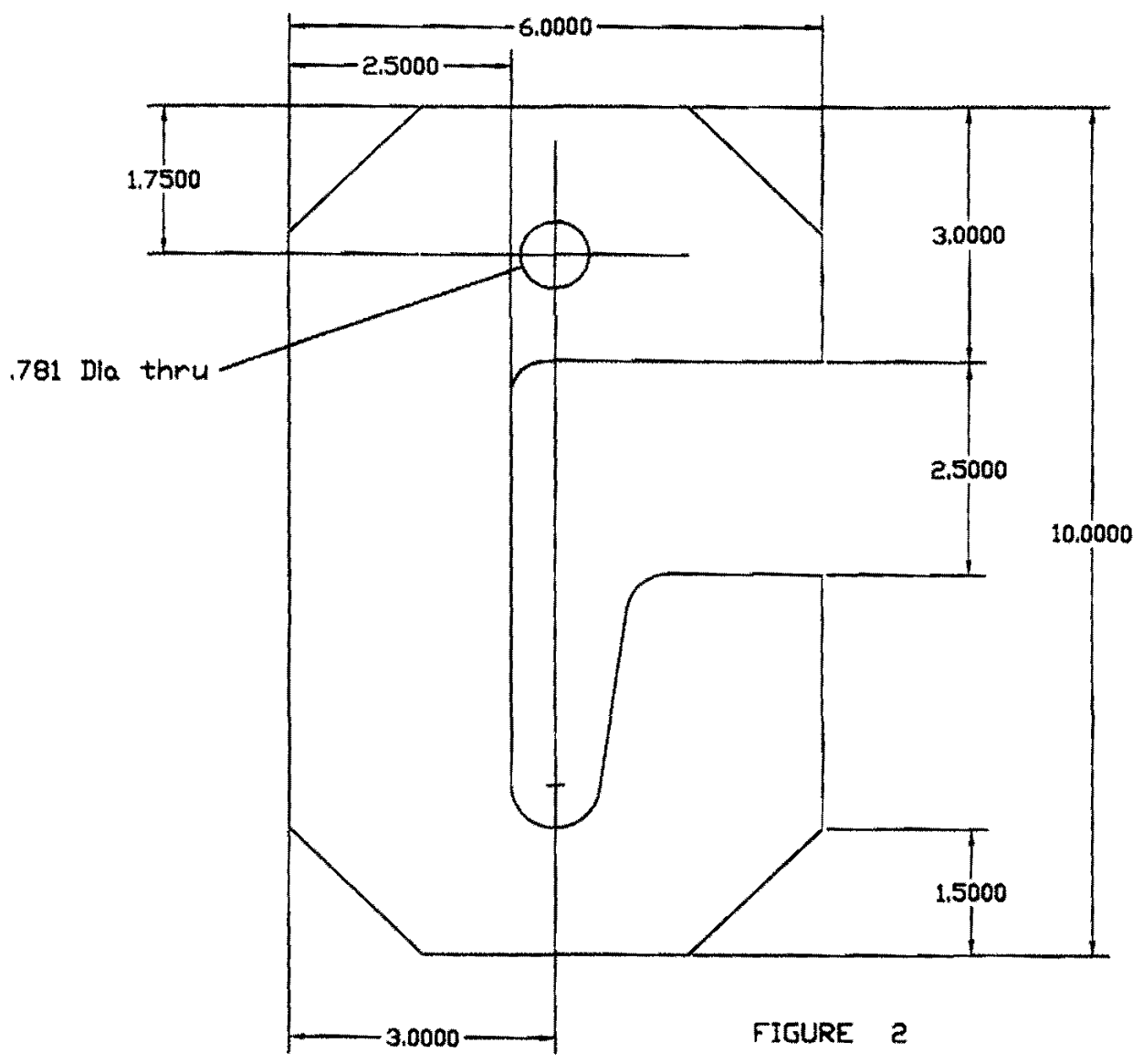

